\title{
A review on: perception and its effect on judgments
}

\author{
Dr. Asha Sharma
}

Assistant Professor, AISSMS Institute of Management, Pune, Maharashtra, India

*Corresponding Author: Asha Sharma

Email: asha.sharma371@gmail.com

\begin{abstract}
Perception is central to understanding how people react. Everyone has certain perceptual tendencies that define the world from our own personal point of view. Values, emotional states, needs and personality all come into play. Characteristic of the object and situation also affect what people select, how people organize what people perceive, and how people make interpretation. Most critical are the errors in judgments people make the world around us. A particularly interesting tendency is how people make causal inferences about what people perceived. People tend to attribute other people's behavior to their personality rather than to situational forces.
\end{abstract}

Keywords: Perception, Biases, Judgment.

\section{Purpose of the Study}

There are many empirical studies by the researchers, nevertheless, so far has not been clubbed well. So, this literature review makes an attempt to club the perception and its effect on judgments.

\section{Introduction}

Perception is a process by which individuals organize and interpret their sensory impressions in order to give meaning to their environment. (Robbins Stephen and et.al. 2009)

Perception is a psychological process of creating an internal image of the outside world. (Tosi Henry L. and Mero Nepal P., 2003).

All perception involves signals in the nervous system, which in turn result from physical stimulation of the sense organs. For example, vision involves light striking the retinas of the eyes, smell is mediated by odour molecules and hearing involves pressure waves. And everyone always try to take shortcuts in decision making. These shortcuts are called as a perceptual bias.

\section{Objectives of the Study}

1. To find out the perception and its effect on judgments.

2. To find out the judgments have significant consequences on the organization.

3. To find out the link between perception and individual decision making.

\section{Research Methodology}

This research paper is concerned with perception and its effect on judgments. This study is a descriptive research design using literature to describe the relationship between the perception and its effect on judgments. This research is made with collection of data's, findings and conclusion in fusion of integrated review of literature. The literature review is collected with the help of online journal database through, EBSCO (Management Research Database) Google scholar and Books etc. highly concentrated on management and organizational reviews on organizational culture.

\section{Literature Review}

Literature review the basic concept of employee's perception and its effect on judgment. Thus, the conceptual background of previous studies were reviewed and summarized from the view point of employee's perception and its effect of judgment.

According to Cha and Carrier (2016), employee's perception of workplace support and working environment affect employee - organizational relationships and, therefore, highly successful organizations generally provide excellent benefits for attracting and retaining employees.

Robbins Stephen P. (2009), what people perceive can be substantially different from objective reality. And attribution theory said that an attempt to determine whether an individual's behavior is internally caused or externally caused. A person uses various shortcuts when they judge others. These techniques are frequently valuable: They allow the people to make accurate perceptions rapidly and provide valid data for making predictions. However they are not foolproof. Understanding these shortcuts can help you recognize when they can result in noteworthy distortion.

\section{Factor influencing perception}

Factors that influence human perception connected to the perceiver, perceived and situation. All these factors are of two kinds:

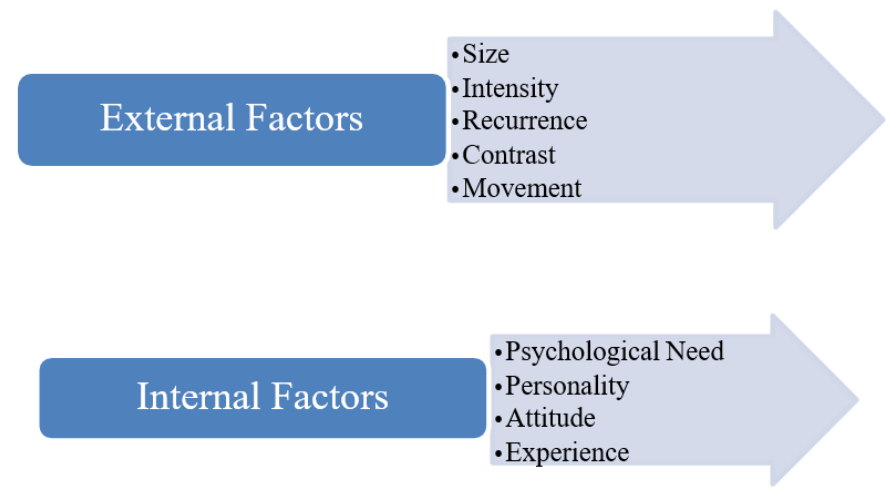

Source: Robbins Stephen P. \& et. al. (2009) 


\section{Stages in the perception process}

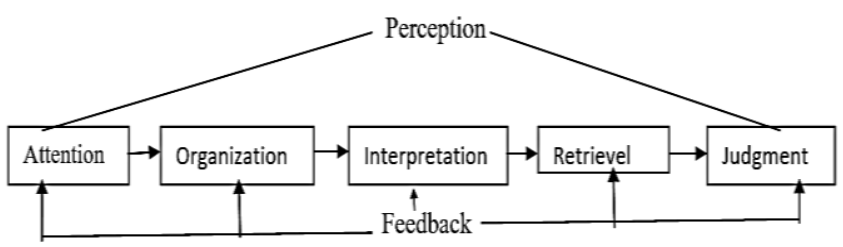

\section{Attention}

The perception process begins with attention. In this stage, people notice some of the information available and filter out the rest. For example: People in a meeting might not notice the fluorescent lights overhead - until the power goes out, leaving them in a dark.

\section{Organization}

As a person pays attention to a stimulus, the person then begins to make sense of it. This begins with the stage in the perception process called organization. During organization, the perceiver sorts the information by using a frame of reference.

\section{Mechanism for organizing stimuli}

To find a pattern in stimuli, people often use a mechanism such as one of the following:

Closure: People tend to perceive incomplete data in a whole, complete form. There is a tendency in all of us to complete incomplete things.

For example, when perceiving the three lines, the tendency to perceive these not as three separate lines but as a triangle. This tendency to create a complete configuration is common because things are perceived as wholes rather than as parts.

Continuity: It is the tendency to perceive objects as continuous patterns. Continuity is a useful organizing principle, but it may also have negative aspects. For example, the tendency to perceive continuous patterns may result in an incapability to perceive uniqueness and detect change. In business and economic forecasting, a common continuity error is to assume that the future will be a simple continuation of current trends and events.

Similarity: When stimuli are like in some way, people tend to group them. For example, in a meeting of ten people, if seven participants are white and three are black, some people may perceive the three black participants as a group whether or not they are similar or related in any other way.

Proximity: Perceptions that are physically close to each other are easier to organize into a pattern or whole. For example, if one person is trouble maker in a company, if newly joined person always together with that person, then boss will be think that trouble maker person affects the newly joined person, and both will be trouble maker for me in future.

\section{Interpretation}

Once attention has been drawn to certain stimuli and person has organized or grouped this information, the next step is to uncover the reasons behind the actions. That is, even if you attention is called to the same information and you organize in the same way your friend does, you may interpret it differently or make different attributions about the reasons behind what you have perceived. For example, as a manager, you might attribute compliments from a friendly subordinate to his being an eager worker, whereas your friend might interpret the behavior as insincere flattery.

\section{Retrieval}

Each of the previous stages forms part of the memory and contributes to the stimuli or information stored there. The information stored in our memory must be retrieved if it is to be used. This leads us to the retrieval stage of the perceptual process.

All of us at times can't retrieve information stored in our memory. More commonly, our memory decays, so that only some of the information is retrieved. For example: based on your prototype about the traits comprising a "high - performing employee" (Hard work, punctuality, intelligence, articulateness, and decisiveness), you may overestimate these traits and underestimate others when you are evaluating the performance of a subordinate whom you generally consider good. Thus, you may overestimate the person's decisiveness since it is a key part of your highperformance prototype.

\section{Judgment}

The perception process ends with judgment. During this stage, the perceiver uses retrieved information to arrive at an overall conclusion.

In the example of your successful project, you hope your boss conclude that your talent and hard work have significantly benefited the organization. To carry out the judgment stage, the perceiver aggregates and weights information.

\section{Person perception: Making judgments about others}

Perception attempt to develop explanation of why things are in a certain way.

Internally Caused Behavior: Whenever behavior of an individual is under his/her control it is known as internally caused behavior. For an instance, coming late in workplace because of oversleep, is an internally influenced behavior.

Externally Caused Behavior: When individual behave because of outside causes is known as externally caused behavior. Foe an instance, coming late in workplace because of traffic jam or some other such reason is an externally influenced behavior.

\section{Attribution theory - Finding causes of behavior}

According to the Kelley's theory of causal attribution, when individuals observe behavior, they attempt to determine whether it is externally or internally caused.

That determination largely depends on three factors:

1. Distinctiveness (More to do with event)

2. Consensus (More to do with people) 
3. Consistency (More to do with time)

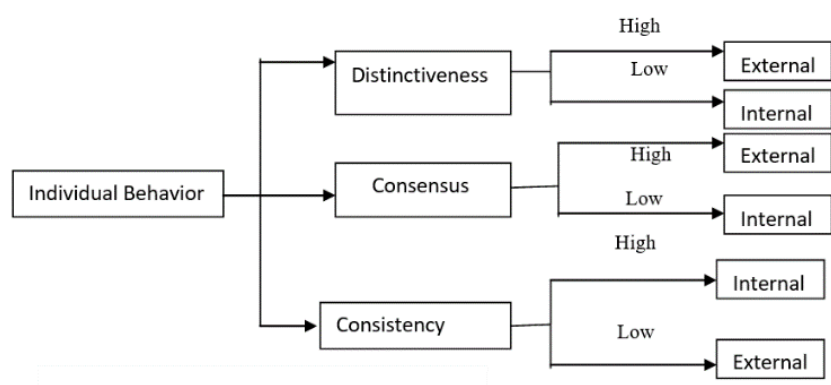

Source: Robbins Stephen P. \& et. al. (2009)

\section{Errors and biases in attributions}

Finding from attribution theory is that errors or biases distort attributions.

\section{Fundamental Attribution Error - (Judging other people's behavior)}

The tendency to undervalue the influence of external factors and overvalue the influence of internal factors when making judgments about the behavior of others. Example, we are more likely to presume that someone who shows up for work late does so because she is lethargic rather than because she got caught in traffic Self- Serving Bias (Judging our own behavior)

Human cannot give credit easily to others. According to self-serving bias people tend to underestimate others.

Because people want to move inferiority to superiority.

\section{A model of attribution theory}

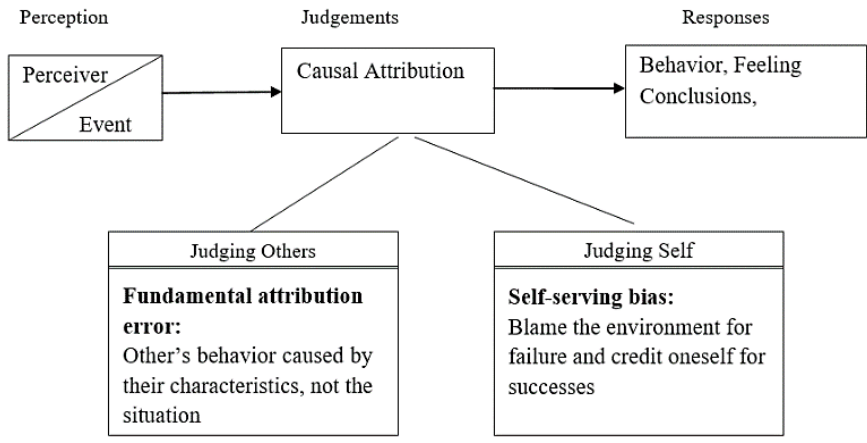

Source: Tosi Henry L. and Mero Nepal P. (2003)

\section{Commonly used shortcuts in judging others}

Perceptual biases: Systematic errors in perceiving others There are numerous systematic biases that interfere with making completely accurate judgments of others. These reflect systematic biases in the ways we think about others in general. Collectively, these biases are referred to as perceptual biases.

\section{Perceptual set}

Perceptual set refers to beliefs about a target based on previous experience with that target. The beliefs could have developed previous association with the target. These general opinions or attitude a person has, constitute the perceptual set.

\section{Halo effect}

The use of one or a few characteristics of a person to affect the valuation of other characteristics is called the halo effect. A halo effects occurs when one attribute of a person is used to develop an overall impression of the individual. The tendency to draw a general impression about an individual on the basis of single characteristic, such as intelligence, fairness, appearance or sociability, a halo effect is operating. Many people find a particular characteristic that they like or dislike strongly in other.

\section{Horn effect}

First impression about a person is negative, People tend to ignore others positive characteristic and concentrate only on the negative ones.

\section{Stereotypes or prototypes}

When people judge someone on the basis of our perception of the group to which he or she belongs, people are using a shortcut called stereotyping. It persists because it is useful, and helps us to organize the world around us. However stereotyping is nothing more than a perpetuation of old prejudices and myths. It is fed by prejudices and ambiguity, and sometimes by threat or fear, and reinforced in many ways.

People rely on generalization every day because they help us to make decision quickly. They are a means of simplifying a complex world. It's less difficult to deal with an unmanageable number of stimuli if people use heuristics or stereotyping types. The problem occurs, when people generalize too much or inaccurately. In organization, people commonly hear comments that represent stereotyping based on gender, age, race, religion, ethnicity, and even weight: "women won't relocate for promotion", "men are not interested in child care", "overweight people lack discipline" and "Older workers can't learn new skills".

\section{Selective perception}

Selective Perception is the tendency to single out those aspects of a situation, person, or object that are consistent with one's needs, values, or attitude. There are different factors that may influence selective perception. Basically, all of a human's previous experiences have an effect on his selective perception mechanism. The tendency to selectively interpret what one sees on the basis of one's interests, experience, backgrounds and attitudes. Selective perception allow us to "speed - read" others, but not without the risk of drawing an inaccurate picture. Because people see what they want to see, people can draw unwarranted conclusions from an ambiguous condition.

\section{Contrast effect}

People also organize information by contrasting it with others information. The other information serves as a reference point for the new information. In the process of 
making these contrasts, perceivers can make perceptual error.

\section{Projection}

Projection is the tendency for people to see their own trait on other people. A classical projection error is illustrated by managers who assume that the needs of their subordinates and their own coincide.

\section{A number of organizational implications of attributional biases and perceptual biases}

People in organization are all the time judging each other. Manager must appraise their employee's performance. People evaluate how much effort our coworkers are putting into their jobs. In numerous cases, our judgments have significant consequences for the organization. Let's in brief look at a few of the main obvious application.

1. Problem Solving and Decision Making

2. Performance Appraisal

3. Managing Workplace Diversity

\section{Problem solving and decision making}

Effectual management requires making good decision when solving problems, and effectual problem - solving requires identifying the most likely cause of the problem. The significance of correct problem identification is obvious: trying to solve the wrong problem will not correct the condition and biased attribution can occur in identifying problems.

For example, a committee will blame other departments or groups when problem occur. At this time, the self serving bias can damage cooperation between groups and fail to uncover the true causes of the problem. Another difficulty in problem identification occurs because people tend, when looking at difficult situations, to interpret them in terms of our own experience and capacity to solve problems.

\section{Performance appraisal}

Attribution biases operate very strongly in performance appraisal. The attribution errors can create serious disagreements between raters and rates about performance in an organization.

\section{Managing workplace diversity}

Perceptual errors are even more critical problems when ethnic or sex differences are added to the condition.

For an example: Other studied uncovered a tendency to attribute female success to hard work or luck rather than to ability. Men, on the other hand, are more protected from adverse evaluation. Interestingly, both women and men make these biased attributions. Their successes usually are attributed to competence, and their failure to bad luck. Such gender - biased attribution insult women and place them at a disadvantage because they are given less credit than men for their skills. From a women's perspective, it is better if her success are attributed to ability, rather than to effort or situational conditions.

\section{The link between perception and individual decision} making

Individual in organization make decisions. That is, they make choices from among two or more alternatives.

1. Top managers determine their organization's goals, what product or service to offer, how best to finance operations, or where to locate a new manufacturing plant.

2. Middle and low level managers determine production schedules, select new employees, and decide how pay raises are to be allocated.

3. Non- managerial employees also make decisions including whether or not to come to work on any given day, how much effort to put forward once at work, and whether or not to comply with a request made by the boss.

4. A number of organizations in recent years have been empowering their non- managerial employees with jobrelated decision - making authority that historically was reserved for managers.

Individual decision making is an important part of organizational behavior. But how individual in organizations make decisions and the quality of their final choices are largely influenced by their perception.

Moreover, every decision requires us to interpret and evaluate information. People typically received data from multiple sources and need to screen, process, and interpret it. Which data, for instances, are relevant to the decision and which are not?

People also need to develop alternatives and evaluate the strengths and weaknesses of each. Again, because alternatives don't come with their strengths and weaknesses clearly marked, an individual decision maker's perceptual process will have a large bearing on the final outcome. Finally, throughout the entire decision making process, perceptual distortion often surface that can bias analysis and conclusion.

\section{Conclusion}

Perception is an important mediating cognitive process. Through this complex process, person makes interpretations of the stimulus or situation they are faced with. Both selectivity and organization go into perceptual interpretations.

How people perceive each other is particularly important for understanding organizational behavior. Person perception is a function of the characteristics of the person perceived, the characteristics of the perceiver, and the situation within which the perception takes place.

Unfortunately, the perceptual process may results in error of judgment or understanding such as in denying the reality of distributing information or by assigning attributes to someone solely on the basis of some category or group to which the person belongs. Fortunately, through training and experience, individual can learn to judge or perceive others more accurately. 
Whether behavior is internally caused by nature of the person or is externally caused by circumstances is an important attribution that people make about the behavior of others, individuals also make attributions concerning task success and failure, which have important implications for organizational behavior.

\section{Areas of further study}

This paper concentrates only on perception and its effect on judgment. In future research other variables can be included for meta-analysis like attitude, performance appraisal and motivation.

\section{Reference}

1. Allport, Gordon. "Attitudes," in A Handbook of Social Psychology, ed. C. Murchison. Worcester, MA: Clark University Press, 1935;789-844.

2. Bruner Jerome S. and Postman Leo, "Emotional Selectivity in Perception and Reaction. J Personal 1947;16(1):69-77.

3. Champoux Joseph E. (2000), "Organizational Behavior: Essential Tenets for a New Millennium", ISBN 981-240-089-3

4. Cha, M. Y., \& Carrier, C. (2016). Contingent faculty perceptions of organizational support, workplace attitudes, and teaching evaluations at public research university. J Study Postsecondary Tertiary Educ 2016;1:121-51.

5. Daft Richard L. and Noe Raymond A., (2001) "Organizational Behavior", ISBN: 0-03-031681-2.

6. Dubrin Andrew J. Fundamentals of Organizational Behaviour", 3 edition, ISBN: 0-324-25992-1.

7. Greenberg Jerald \& Baron Robert A. 2008, "Behavior in Organizations", ninth edition, ISBN - 978-81-203-3835-7.

8. Hellriegel Don \& Slocum John W. (2004), "Organizational Behavior", Tenth Edition, ISBN:0- 324-15684-7.

9. Luthans Fred, 1998, “Organizational Behavior", Eighth Edition, ISBN 0-07-039184 - X. (Mc Graw - Hill International edition)
10. Moorhead Gregory, Griffin Ricky W. Organizational Behavior Managing People and Organizations", Third Edition, ISBN 817224-173-9.

11. Nahavandi Afsaneh, Malekzadeh Ali R. (1998), "Organizational Behavior: The person- Organization Fit", ISBN 0-13-285982-3.

12. Osborn Richard N., Hunt James G, \& Schermerhorn John R. (2005), "Organizational Behavior", Ninth Edition, ISBN 0471-70150-5.

13. Pareek Udai, (2004), "Understanding Organizational Behaviour. ISBN- 0-19-566776-X.

14. Pronin Emily. "Perception and misperception of bias in human judgment", Trends in Cognitive Sciences, Department of Psychology, Princeton University, Green Hall, Princeton, USA, 2007;11(1):37-43.

15. Robbins Stephen P. Judge Timothy A, Sanghi Seema, (2009), "Organizational Behavior", $13^{\text {th }}$ edition, ISBN: 9780136007173.

16. Shore Lynn McFarlane, Barksdale Kevin, Shore Ted H. Managerial Perceptions of Employee Commitment to the Organization. Acad Manag J 1995;38(6):1593-1615.

17. Stroh Linda K., Northcraft Gregory B. \& Neale Margaret A., (2001), "Organizational Behavior: A Management Challenge", Third Edition, ISBN 0-8058-3829-5.

18. Tosi H L, Rizzo JR, Carrol SJ, 2000, "Handbook of Organizational Behaviour", ISBN 81-87233-34-6.

19. Waller Mary J, Huber George P, Glick William H. Functional Background as A Determinant of Executives Selective Perception. Acad Manag J1995;38(4):943-74.

How to cite this article: Sharma A. A review on: perception and its effect on judgments. J Manag Res Anal 2019;6(4):164-8. 